\title{
Reliability of current estimates of schistosomiasis prevalence in the Rainforest Zone of the state of Pernambuco, Northeastern Brazil
}

\author{
Tereza C Favre/+ , Ricardo AA Ximenes*, Aline F Galvão, Ana Paula B Pereira, \\ Tereza N Wanderlei**, Constança S Barbosa***, Otávio S Pieri
}

\author{
Departamento de Biologia, Instituto Oswaldo Cruz-Fiocruz, Av. Brasil 4365, 21045-900 Rio de Janeiro, RJ, Brasil \\ *Departamento de Medicina Tropical, Universidade Federal de Pernambuco, Recife, PE, Brasil **Laboratório de Endemias, \\ Secretaria de Saúde de Pernambuco, Recife, PE, Brasil ***Departamento de Parasitologia, Instituto Aggeu Magalhães-Fiocruz, \\ Recife, PE, Brasil
}

The Program for Schistosomiasis Control within the Unified Health System (PCE-SUS) was implemented by 1999 in the Rainforest Zone or "Zona da Mata" of Pernambuco (ZMP) aiming to carry out biennial stool surveys of whole populations through municipal health organs followed by treatment of the positives through the local units of the Family Health Program (PSF). Yearly reports from the Health Department of Pernambuco State (SES/PE) from 2002 to 2004 on the PCE-SUS surveys were assessed to evaluate whether the current estimates of prevalence in the municipalities of the ZMP are based on reliable samples so as to allow considerations on the real situation of schistosomiasis in that area. The surveys carried out in that period did not follow the major principles underlying sampling design, thus posing problems in both precision and validity of the estimates. Only 12 out of 43 municipalities had minimally reliable estimates: five with moderate prevalence (10-50\%) and seven with low prevalence (< $10 \%$ ). Surveys with appropriate sampling procedures aimed either at representative target groups (school-aged children) or communities are recommended for the ZMP and other endemic areas not only to provide reliable information on the current situation of schistosomiasis but also to plan adequate control strategies.

Key words: schistosomiasis - soil-transmitted helminthes - prevalence - Pernambuco - Brazil

The Rainforest Zone ("Zona da Mata") of the state of Pernambuco (ZMP), also known as sugar-cane zone, encompasses 43 municipalities occupying $8.6 \%$ of its area. By 2000 population of the ZMP was estimated at 1.2 million, $31 \%$ of which living in rural areas. Of the estimated 280 thousand households $46 \%$ had no piped-water supply and $75 \%$ were not connected to the general sewage network. The average family earnings were 1.6 times the minimum national wage. (www.ibge.gov.br). The main economic activity in the ZMP is the production of sugar cane and its by-products (Condepe 2000).

The ecological features of the ZMP are relatively homogeneous. The climate is tropical, warm and humid with two well-defined (rainy and dry) seasons. The vegetation prevailing in the first centuries of colonization (tropical rainforest) has been extensively degraded due to sugarcane planting. The land is mainly undulated with hills varying from 10 to $350 \mathrm{~m}$ of height. Its geological constitution is predominantly crystalline originated from the preCambrian period. The main water-bodies are perennial rivers running eastwards into the Atlantic Ocean. In general they are heavily polluted as a result of disorderly urban growth and sugar-cane production (Condepe 2000).

${ }^{+}$Corresponding author: tfavre@ioc.fiocruz.br

Received 25 May 2006

Accepted 26 June 2006
Schistosomiasis remains one of the most prevalent endemic diseases in the ZMP regardless successive control campaigns carried out by the Ministry of Health $(\mathrm{MoH})$ since 1977 (Favre et al. 2001). The last evaluation made by the $\mathrm{MoH}$ through the national Health Foundation (Funasa) between 1996 and 1999 revealed that 35 of the municipalities still had prevalence indices above $10 \%$ (Favre et al. 2006).

By 1999, the MoH decentralized the activities of surveillance and control by creating the Integrated Covenanted Program for Epidemiology and Disease Control (PPI/ECD). As a result, the municipalities became responsible for the management and implementation of those activities through the Program for Schistosomiasis Control within the Unified Health System (PCE-SUS).

In endemic areas such as the ZMP, the PCE-SUS activities involve two main steps: (i) biennial stool surveys of whole populations at the locality level through municipal health organs and (ii) treatment of the positives through the local health units of the Family Health Program (PSF) (Barbosa et al. 2006a). Each PSF unit attends up to one thousand families or households. It should be noted that for the purpose of surveillance and control of endemic diseases locality may be defined as an area having its own denomination and well marked (either natural or artificial) boundaries (Sucam 1983).

In the ZMP, PCE-SUS activities were initiated in 2001. According to the Computerized System of the Schistosomiasis Control Program (SISPCE) (http://dtr2001. saude.gov.br/svs/epi/esquis/esquis00.htm), until 2004 100,932 persons had been examined, 13,828 (13.7\%) of 
which being positive for Schistosoma mansoni. Among these $2129(20.8 \%)$ harboured more than 100 eggs per gram of feces (epg). As regards soil-transmitted helminthes (STH), 14,869 (14.7\%) exams were positive for Ascaris lumbricoides, 5668 (5.6\%) for Trichuris trichiura, and $2651(2.6 \%)$ for hookworms.

The data made available at SISPCE are an informative summing up of the PCE-SUS activities at the municipality level or higher, and cannot be mistakenly used for estimating prevalence. Even considering that there is some degree of standardization in the data collection, some major principles underlying sampling design are not being followed: a sample size to achieve a certain degree of precision was not estimated, a random method is not being used for sampling and some sections of the population are being left out (Moser 1985). These facts pose several problems in the estimation of disease frequency related either to random error - a problem of precision and to systematic error - a problem of validity (Kleinbaum 1982).

A population may be considered as composed of a hierarchy of sample units of different sizes and types (Moser 1985). In our case the population of this area is made up of the population of the municipalities, which is composed of the population of a number of localities, each of which is formed by a number of individuals. Several techniques of sample design may be used to select individuals but in this case it is often desirable to include, in a first stage, the selection of municipalities or localities, and then to take all individuals or just a sub-sample of individuals in each locality previously selected. Choosing one sampling scheme implies several technical considerations, like the way which variability between and within localities may affect the precision of the estimate (Ximenes \& Araújo 1995). As fieldworkers may not be familiar with the fundaments of sample design some practical schemes have been proposed to facilitate the conduction of surveys. For instance, the World Health Organization (Montresor et al. 1998, 2002, WHO 2002) propose a minimum number of sampled localities and a minimum number of exams per locality, so that the prevalence estimates about the municipality can be regarded as reliable. As the PCE-SUS has no readily available data on individuals, families or age groups we will limit our comments mainly to some aspects related to the sample size and selection bias.

The present work aims to evaluate whether the current estimates of prevalence in the municipalities of the ZMP are based on minimally reliable samples so as to allow considerations on the real situation of schistosomiasis in that important endemic area.

\section{MATERIALS AND METHODS}

Information about the PCE-SUS activities in the ZMP was obtained from the annual reports by the Health Department of Pernambuco State (SES/PE) for the period of 2002-2004. The data on number of examined persons, number of positives for $S$. mansoni and STH, namely $A$. lumbricoides and hookworms, were tabulated by microregion (North, Centre and South), municipality, year and locality. Prevalence of infection by S. mansoni and each
STH, as defined by Montresor et al. (2002), was calculated through the Systat 11 statistical software.

Reliability of the municipality data was evaluated according to the criteria proposed by Lwanga and Lemeshow (1991), Montresor et al. (2002) e WHO (2002) for prevalence surveys. Thus, only prevalence indices from those municipalities where a minimum of 55 persons were examined in at least five localities ( 275 exams) were considered as minimally reliable. This is the minimum sample size required for detecting $10 \%$ prevalence at a confidence level of $0.95(95 \%)$, error of $0.05( \pm 5 \%)$ and design effect of two (Lwanga \& Lemeshow 1991). The municipalities with minimally reliable data were categorized according to the classes of prevalence recommended by WHO (2002). For S. mansoni: $<10 \%$ (low), $10-50 \%$ (moderate), and $>50 \%$ (high).

\section{RESULTS}

Data on the number of persons examined by the PCESUS in the municipalities of the ZMP from 2002 to 2004 are given by Favre et al. (2006).

Fig. 1 shows the approximate location of those localities in the ZMP where at least 55 persons were examined in the 2002-2004 period. Only 12 out of 43 municipalities carried out surveys in at least five localities over that period. The municipalities were: Aliança, Tracunhaém, and Lagoa do Carro in the North micro-region, Chã de Alegria, Glória de Goitá and Chã Grande in the Centre micro-region, and Belém de Maria, Catende, Escada, Gameleira, Ribeirão and São Benedito do Sul in the South micro-region. All of them covered localities along most of their territorial area. In eight of those municipalities the total of persons examined exceeded $10 \%$ of the population: Aliança (15.9\%), Tracunhém (39.8\%), Lagoa do Carro (36\%), Chã de Alegria (62.8\%), Chã Grande (11.8\%), Glória de Goitá (18.4\%), Belém de Maria (99.1\%) and Catende (24.9\%).

The Table presents prevalence data from the annual reports of the SES/PE in the period of 2002-2004 for the municipalities attended by the PCE-SUS in the ZMP, as well as the corrected data according to the criteria for minimum reliability. For 2002, only three of the 43 municipalities had minimally reliable estimates. For 2003 and 2004 seven municipalities achieved that criterion. In municipalities where the estimates were minimally reliable the differences in prevalence between the SES/PE data and the corrected data were around 1 percentage point (pp). The only exception was Gameleira, where the corrected prevalence for 2003 was 7.9 pp above the SES/PE estimate.

\section{DISCUSSION}

The annual reports made by the SES/PE are meant to provide technical information about the activities of diagnosis and treatment carried out by the PCE-SUS in the endemic area of schistosomiasis in Pernambuco. Therefore, such reports can only be regarded as a trustworthy source of prevalence estimates if their data are based on surveys that comply with the basic principles of sampling.

The problems found with the surveys carried out by the PCE-SUS in the ZMP hamper the reliability of the current estimates of schistosomiasis prevalence in the fol- 
lowing aspects: first, six municipalities have not been surveyed at all, leaving them without any prevalence estimate since the 1996-1999 survey; second, the surveys carried out in 25 municipalities did not comply with the criteria for minimum reliability, and therefore cannot be used as a trustworthy source of information. Third, the selection of municipalities, localities and individuals was not based on a random method. These aspects together lead not only to a loss of precision but also to a limitation in the population coverage which may bias the estimation of the prevalence.

The situation of four municipalities, namely Paudalho,
Vitória de Santo Antão, Quipapá, and Escada, may illustrate the issues involved:

Paudalho was surveyed in 2004, and only 11 of the 88 existing localities were covered. Six of those had $100 \%$ of prevalence, based on less than five exams in each. The high prevalence found in such small samples was clearly due to passive case detection by the local health service and not an active search by the PCE-SUS. As a result, prevalence was probably overestimated both at the locality and the municipality level.

Vitória de Santo Antão was likewise surveyed in 2004, but only two of the 176 localities were covered: the capital

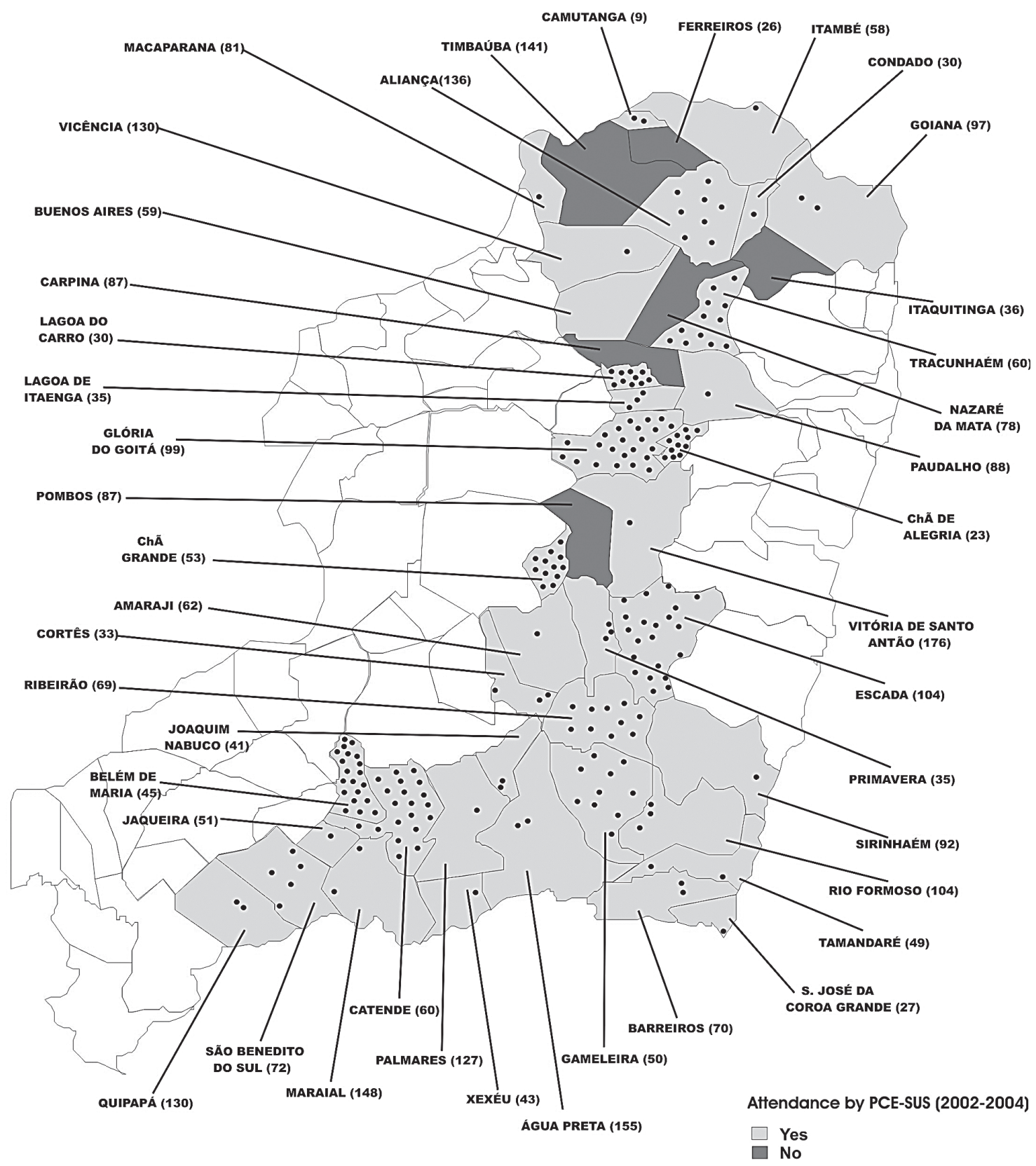

Fig. 1: localities (circles) with coverage by the Program for Schistosomiasis Control within the Inified Healt System (PCE-SUS) of at least 55 exams from 2003 to 2004 in the municipalities of the Rainforest Zone ("Zona da Mata") of the state of Pernambuco, Northeastern Brazil. The values in parentheses indicate the number of existing localities. 
TABLE

Prevalence (\%) of schistosomiasis from 2002 to 2004 in the municipalities of the Rainforest Zone ("Zona da Mata") of the state of Pernambuco, Northeastern Brazil, by micro-region (North, Centre, and South). The values under the SES/PE heading are from all localities included in the annual reports of the Health Department of Pernambuco State. The corrected values include only data from the surveys in which at least 55 persons were examined in five localities or more

\begin{tabular}{|c|c|c|c|c|c|c|c|}
\hline \multirow{2}{*}{\multicolumn{2}{|c|}{ Municipalities }} & \multicolumn{2}{|c|}{2002} & \multicolumn{2}{|c|}{2003} & \multicolumn{2}{|c|}{2004} \\
\hline & & \multirow{2}{*}{$\begin{array}{c}\mathrm{SES} / \mathrm{PE} \\
8.1\end{array}$} & \multirow{2}{*}{$\frac{\text { Corrected }}{\text { UD }}$} & \multirow{2}{*}{$\begin{array}{c}\text { SES/PE } \\
21.6\end{array}$} & \multirow{2}{*}{$\begin{array}{c}\text { Corrected } \\
\text { UD }\end{array}$} & \multirow{2}{*}{$\frac{\mathrm{SES} / \mathrm{PE}}{26.2}$} & \multirow{2}{*}{$\frac{\text { Corrected }}{\text { UD }}$} \\
\hline North & Aliança & & & & & & \\
\hline & Buenos Aires & - & - & - & - & 20.0 & UD \\
\hline & Camutanga & - & - & 2.5 & UD & 2.0 & UD \\
\hline & Condado & - & - & 13.2 & UD & 17.5 & UD \\
\hline & Goiana & - & - & - & - & 12.1 & UD \\
\hline & Itambé & - & - & 14.2 & UD & 10.9 & UD \\
\hline & L. Itaenga & - & - & - & - & 5.8 & UD \\
\hline & L. Carro & 3.4 & UD & 9.6 & 9.9 & 10.4 & UD \\
\hline & Macaparana & - & - & 5.6 & UD & 5.4 & UD \\
\hline & Paudalho & - & - & - & - & 28.9 & UD \\
\hline & Tracunhaém & - & - & 17.3 & 16.4 & 4.3 & UD \\
\hline & Vicência & - & - & - & - & 25.4 & UD \\
\hline \multirow[t]{4}{*}{ Centre } & Chã Alegria & 9.7 & 9.0 & 10.3 & 9.9 & 5.9 & UD \\
\hline & Chã Grande & 3.9 & UD & 3.0 & UD & 0.36 & 0.4 \\
\hline & Glória Goitá & - & - & 9.0 & 9,0 & - & - \\
\hline & V. S. Antão & - & - & - & - & 13.6 & UD \\
\hline \multirow[t]{21}{*}{ South } & Água Preta & - & - & - & - & 13.4 & UD \\
\hline & Amaraji & 100.0 & UD & - & - & 12.4 & UD \\
\hline & Barreiros & - & - & 34.6 & UD & 5.3 & UD \\
\hline & Belém Maria & 14.4 & UD & 11.9 & 12.0 & 11.2 & 11.4 \\
\hline & Catende & 13.0 & 13.0 & 8.5 & UD & 4.6 & 4.6 \\
\hline & Cortês & - & - & - & - & 12.8 & UD \\
\hline & Escada & 36.9 & 34.6 & 43.2 & 42.9 & 21.7 & 22.3 \\
\hline & Gameleira & - & - & 50.5 & 58.4 & 14.1 & 14.1 \\
\hline & Jaqueira & - & - & - & - & 13.3 & UD \\
\hline & J. Nabuco & - & - & - & - & 12.1 & UD \\
\hline & Maraial & - & - & 15.9 & UD & 15.9 & UD \\
\hline & Palmares & - & - & - & - & 6.6 & UD \\
\hline & Primavera & - & - & - & - & 7.0 & UD \\
\hline & Quipapá & 6.3 & UD & - & - & 4.2 & UD \\
\hline & Ribeirão & - & - & 14.7 & UD & 8.3 & 8.3 \\
\hline & Rio Formoso & - & - & - & - & 49.8 & UD \\
\hline & S. B. do Sul & - & - & - & - & 9.9 & 10.5 \\
\hline & S.J.C. Grande & - & - & - & - & 0 & UD \\
\hline & Sirinháem & - & - & - & - & 1.3 & UD \\
\hline & Tamandaré & - & - & - & - & 10.0 & UD \\
\hline & Xexéu & - & - & - & - & 5.3 & UD \\
\hline \multicolumn{2}{|l|}{ Total } & 9 & 3 & 17 & 7 & 36 & 7 \\
\hline
\end{tabular}

UD: unreliable data; - : municipalities not attended by the PCE-SUS; SES/PE: Healt Department of State of Pernambuco.

town, with 6540 inhabitants and Natuba, a rural village with 665 residents. In the former, prevalence was reported as $100 \%$ based on the exam of only one person obviously attended by the routine health service. In the latter, 43 $(13.4 \%)$ out of 322 exams done by active search were positive. This result is not necessarily representative of the Natuba population as it is not clear which criteria were used to select those individuals. For the municipality as a whole, the data from the two localities were added together totaling 323 exams and $44(13.6 \%)$ positives. Under no circumstance this result should be regarded as representative of the municipality.
Quipapá has 130 localities totaling 20 thousand residents, more than half of them living in rural areas. The PCE-SUS examined 2332 persons in 2002 and 1480 in 2004, reporting respectively 6.3 and $4.2 \%$ of prevalence. At first sight this indicates a fall of $2.1 \mathrm{pp}$ in the municipality prevalence over that period. Considering that the last survey carried out by the MoH in 1996-1999 registered $23.5 \%$ of prevalence (Favre et al. 2006), those results may be mistakenly regarded as indication that schistosomiasis has recently ceased to be a relevant health problem in that municipality. However, a closer look at the SES/PE reports shows that both surveys were carried out in the 
capital town, which is mainly urban. Although the sample sizes were considerable, the area chosen for the surveys prevented the highly vulnerable rural population from being sampled. Therefore, the SES/PE data cannot be used to assess the present situation of schistosomiasis in that municipality.

Escada was surveyed for three consecutive years and more than five localities were covered by year. At least 55 persons were examined in each of those localities. The corrected prevalence indices were $34.6 \%$ for $2002,42.9 \%$ for 2003 , and $22.3 \%$ for 2004 (Table). Even considering those estimates as minimally reliable, they cannot provide information on the recent evolution of the prevalence because the yearly data originate from different localities according to the SES/PE reports.

In view of currently available information from the SES/PE, minimally reliable estimates for the 2002-2004 period can be better achieved if the data are considered together instead of year-by-year. As precaution, only those municipalities that surveyed at least 55 persons in each of five of more localities over that period may be included. However, for the reasons already mentioned these results are not without concern; they may be regarded not as adequate but as the best estimate available.

Only 12 municipalities have reached the above criteria, three in the North micro-region, three in the Centre micro-region and six in the South micro-region. Five of them fell into the moderate prevalence class and the remaining seven, in the low prevalence one (Fig. 2).

Even considering that the surveys carried out by the MoH in the ZMP from 1996 to 1999 (Favre et al. 2006) had a broader scope than those by the PCE-SUS from 2002 to 2004, a decrease in prevalence between the two periods can be envisaged for 11 of those 12 municipalities. Only in Escada an apparent increase was noticed, from 22.8 to $34.4 \%$. However, surveys employing proper sampling techniques are required to confirm this hypothesis.
As the SES/PE also reports information on infection by A. lumbricoides and hookworms, prevalence data from those 12 municipalities are given in Fig. 3. These results are in agreement with the relatively moderate levels of STH previously found in the sugar-cane zone of Pernambuco (Zani et al. 2004) and fully justify the strategy of combining schistosomiasis and STH control in the ZMP as recommended by WHO (2002).

The main limitations faced by the PCE-SUS in the ZMP are due to dearth of local recourses both material and human. Such problems must be overcome in the short term not only to attend the increasing demand for diagnosis

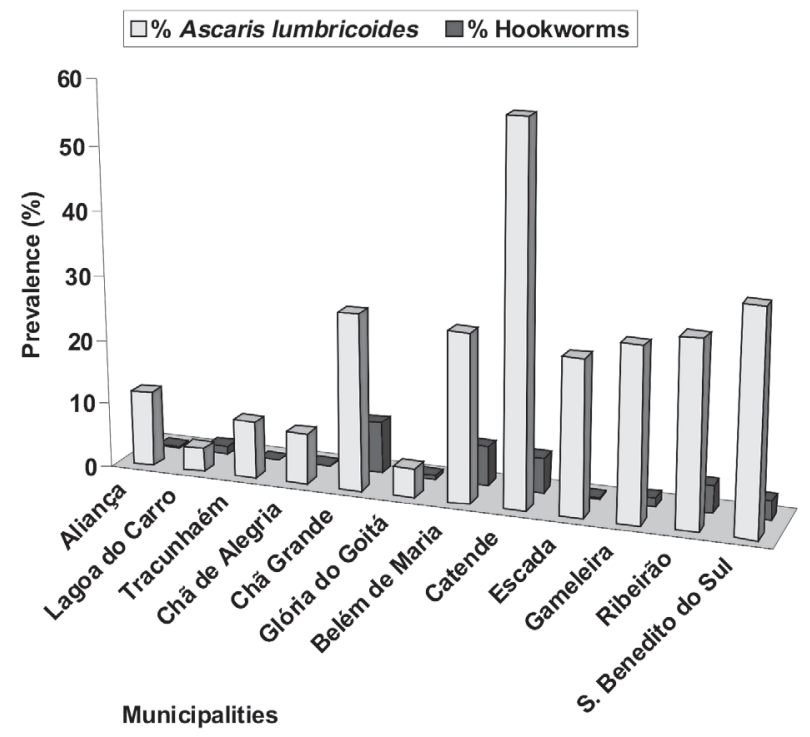

Fig. 3: prevalence of soil-transmitted helminth (STH) infection in the Rainforest Zone ("Zona da Mata") of the state of Pernambuco, Northeastern Brazil. Only the municipalities attended by the PCESUS (2002-2004) in five or more localities with at least 55 exams in each were considered.

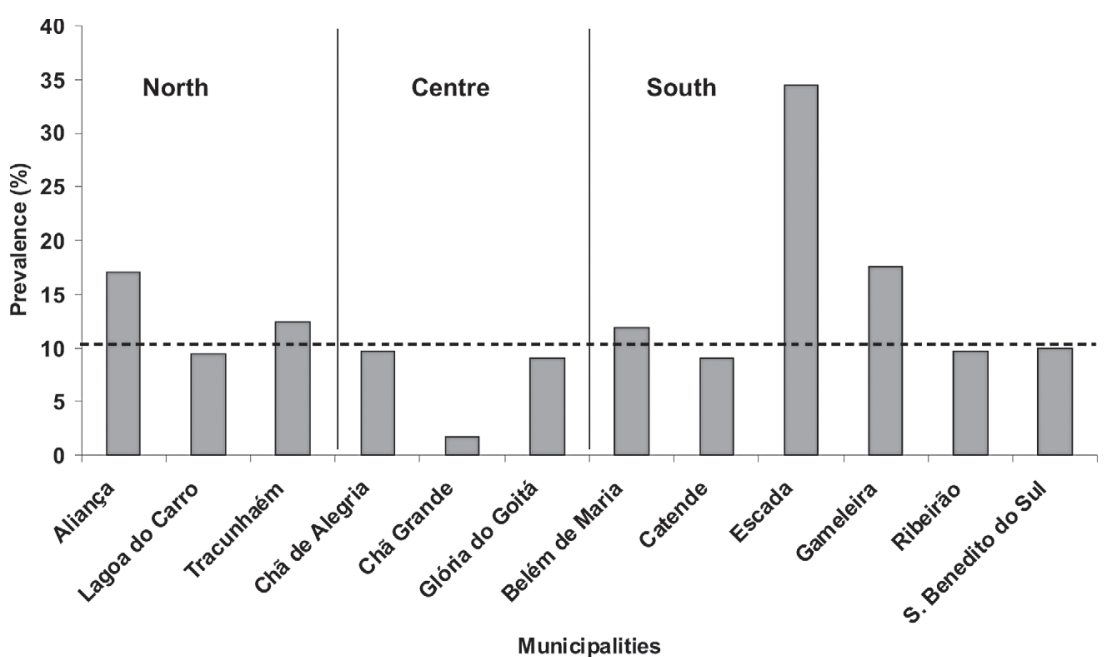

Fig. 2: prevalence of Schistosoma mansoni infection in the Rainforest Zone ("Zona da Mata") of the state of Pernambuco, Northeastern Brazil. Only the municipalities attended by the PCE-SUS (2002-2004) in five or more localities with at least 55 exams in each were considered. The dashed line indicates the lower threshold (10\%) for moderate prevalence of schistosomiasis. 
and treatment, but also to provide trustworthy information on the current status of schistosomiasis in that endemic area. The lack of reliable estimates about schistosomiasis has also been a matter of concern in other endemic areas of this Country, indicating the need of a prevalence survey at the national level (Katz \& Peixoto 2000).

Reliable estimates of schistosomiasis prevalence classes can be cost-effectively obtained by means of appropriate sampling procedures aimed either at school-aged children (WHO 2002) or communities (Bennet et al 1991, Brooker et al 2005). Such techniques minimize the problems of precision and validity, and can be easily executed by the PCE-SUS. A recent study involving school surveys among 9-12 yrs old children in all 43 municipalities of the ZMP (Barbosa et al. 2006b) identified 25 (58\%) of them in the moderate prevalence class and the remaining, in the low prevalence one. Surveys based on representative samples enable not only to know the real situation of schistosomiasis but also to suggest adequate control strategies.

\section{REFERENCES}

Barbosa CS, Favre TC, Pieri OS, Amaral RS 2006a. Epidemiologia e controle da esquistossomose no Brasil. In HL Lenzi, OS Carvalho, PMZ Coelho (eds), Esquistos-somose, Fiocruz, Rio de Janeiro, in press.

Barbosa CS, Favre TC, Wanderley TN, Pieri OS 2006b. Assessment of schistosomiasis in the Forest Zone of Pernambuco through school surveys. Mem Inst Oswaldo Cruz 101 (Suppl. I): 55-62.

Bennet S, Woods T, Liyanage WM, Smith D 1991. A simplified method for cluster-sample surveys of health in developing countries. Rapp Trimest Statist Sanit Mond 44: 98-106.

Brooker S, Katabereine NB, Myatt M, Stothard JR, Fenwick A 2005. Rapid assessment of Schistosoma mansoni: the validity, applicability and cost-effectiveness of the Lot Quality Assurance Sampling method in Uganda. Trop Med Internal Health 10: 647-658.

Condepe 2000. Mesorregião da Mata Pernambucana: Microrregião da Mata Setentrional, da Mata Meridional e de Vitória de Santo Antão. Monografia Mesorregional. Instituto de Planejamento de Pernambuco, Recife, 120 p.
Favre TC, Pieri OS, Barbosa CS, Beck L 2001. Avaliação das ações de controle da esquistossomose implementadas entre 1977 e 1996 na área endêmica de Pernambuco, Brasil. Ver Soc Bras Med Trop 34: 569-576.

Favre TC, Ximenes RAAR, Galvão AF, Pereira APB, Wanderley TN, Barbosa CS, Pieri OS 2006. Attaining the minimum target of resolution WHA 54.19 for schistosomiasis control in the sugar-cane zone of Pernambuco, Northeastern Brazil. Mem Inst Oswaldo Cruz 101 (Suppl. I): 125-132.

Funasa 1998. Controle da Esquistossomose. Diretrizes Técnicas, 2nd ed., Ministério da Saúde, Brasília, 70 pp.

Katz N, Peixoto SV 2000. Análise crítica da estimativa do número de portadores de esquistossomose mansoni no Brasil. Rev Inst Med Trop São Paulo 33: 303-308.

Kleinbaum DG, Kupper LL, Morgenstern H 1982. Epidemiologic Research. Principles and Quantitative Methods, Van Nostrand Reinhold, New York, 560 pp.

Lwanga SK, Lemeshow S 1991. Determinacion del Tamaño de las Muestras en los Estudios Sanitarios: Manual Practico, Organization Mundiale del Salud, Genebra, 80 pp.

Montresor A, Crompton DWT, Bundy DAP, Hall A, Savioli L 1998. Guidelines for the Evaluation of Soil-transmitted Helminthiasis and Schistosomiasis at Community Level. A Guide for Managers of Control Programmes, Worl Health Organization, Geneva, WHO/CDS/SIP/98.1.

Montresor A, Crompton D, Gyorkos TW, Saviolli L 2002. Helminth Control in School-age Children: A guide for Managers of Control Programmes, World Health Organization, Geneva, 73 pp.

Moser CA, Kalton G 1985. Survey Methods in Social Investigation, Gower Publishing, England.

Sucam 1983. Manual de Reconhecimento Geográfico, Ministério da Saúde, Brasília, 18 pp.

WHO 2002. Prevention and Control of Schistosomiasis and the Soil-transmitted Helminthiasis, Report of a WHO Expert Committee, World Health Organization, Geneva, 73 pp.

Zani LC, Favre TC, Pieri OT, Barbosa CS 2004. Impact of antihelminthic treatment on infection by Ascaris lumbricoides, Trichuris trichiura and hookworms in Covas, a rural community of Pernambuco, Brazil. Rev Inst Med Trop São Paulo 46: 63-71. 